\title{
Polymorphisms in Toxoplasma gondii: role of atypical strains in unusual clinical manifestations of toxoplasmosis
}

\author{
Claudio Bruno Silva de Oliveira[1]
}

\begin{abstract}
[1]. Laboratório de Biologia da Malária e Toxoplasmose, Departamento de Microbiologia e Parasitologia, Centro de Biociências, Universidade Federal do Rio Grande do Norte, Natal, RN, Brasil.
\end{abstract}

\section{Dear Editor,}

I recently had the opportunity to read the article entitled "An atypical Toxoplasma gondii genotype in a rural Brazilian dog co-infected with Leishmania (Viannia) braziliensis," an article published in the Journal of the Brazilian Society of Tropical Medicine by Silva et al. ${ }^{1}$. I think that it is of great importance that the authors researched and sought possible polymorphisms in parasites isolated from animals. In such cases, it is common to note that these parasites are often also found in humans ${ }^{2}$. I consider it great because for a long time it was thought that Toxoplasma gondii typically had a clonal lineage, with four main groups scattered mainly in Europe and North America ${ }^{3,4}$.

Recently, several studies have shown that in South America, especially Brazil, there are a considerable number of parasite isolates with atypical features compared to those observed in Europe and North America ${ }^{2,5}$. Much of this research has been based on the isolation of the parasite from livestock or even pets. This fact, apparently, is not surprising, since these animals live in close proximity to humans, and these farm animals are often consumed without taking the necessary precautions to ensure the destruction of parasite cysts in the meat of infected animals.

In the State of Rio Grande do Norte, Brazil, I have observed with great concern the emergence of unusual toxoplasmosis profiles. In a study published in $2014^{6}$, it was observed that patients from an eye clinic, who were diagnosed with ocular toxoplasmosis had a higher incidence of bilateral ocular lesions, which is a deviation from its classic unilateral ocular presentation. It is also of great concern to note that many of these patients are asymptomatic and associated with congenital infection, which increases the concern about other forms of damage that may arise in patients if diagnosed late. These different clinical patterns generate many questions. For instance, does this happen because of the different populations of the parasites, or are they due to characteristics of the hosts?

Recently, in order to seek clarification to some of these questions in this state, some studies have been developed in

Corresponding author: Prof. Claudio Bruno Silva de Oliveira.

e-mail: bruno_biomedico@yahoo.com.br

Received 26 May 2016

Accepted 27 June 2017 order to characterize genetically distinct parasite populations circulating in livestock ${ }^{5,7}$. In these studies, we observed that there is a great genetic variability within protozoan populations in this region. From evaluations performed in a murine model, it was verified that these parasites have different levels of pathogenicity and resistance to standard treatment. Parasites with genetic profiles similar to those observed here were also found in Fernando de Noronha Island and the State of Rondônia, which is almost 5,000 kilometers away, thus demonstrating the great capacity of the parasite to spread to distant regions ${ }^{5}$. Therefore, there is the need to urgently establish some clinical correlation in this regard, including the locally prevalent strains of the parasite, as well as those in different parts of the country. This information will be critical in high-risk groups, including pregnant women and immunosuppressed patients, who typically experience more severe clinical manifestations of toxoplasmosis.

Thus, I reiterate that studies of this kind are essential for broadening our knowledge of this disease in different regions. These studies provide information on parasite biology, which together with the clinical manifestations and characteristics within each region, give clarity about this disease, especially during atypical presentations in high-risk populations. Moreover, I also propose that health authorities prioritize the early diagnosis of the disease in order to reduce the problems associated with congenital toxoplasmosis in asymptomatic cases in higher risk areas.

Conflict of interest

The author has no conflicts of interest to declare.

\section{REFERENCES}

1. Silva RCD, Caffaro K, Paula CL, Risseti RM, Langoni H, Megid J, et al. An atypical Toxoplasma gondii genotype in a rural Brazilian dog co-infected with Leishmania (Viannia) braziliensis. Rev Soc Bras Med Trop. 2015;48(2):224-7.

2. Silva LA, Andrade RO, Carneiro ACA, Vitor RW. Overlapping Toxoplasma gondii genotypes circulating in domestic animals and humans in southeastern Brazil. PLoS One. 2014;9(2):e90237.

3. Howe DK, Sibley LD. Toxoplasma gondii comprises three clonal lineages: correlation of parasite genotype with human disease. J Infect Dis. 1995;172(6):1561-6. 
4. Khan A, Dubey JP, Su C, Ajioka JW, Rosenthal BM, Sibley LD. Genetic analyses of atypical Toxoplasma gondii strains reveal a fourth clonal lineage in North America. Int J Parasitol. 2011;41(6):645-55.

5. Clementino Andrade MM, Pinheiro BV, Cunha MM, Carneiro ACAV, Andrade Neto VF, Vitor RWA. New gentotypes of Toxoplasma gondii obtained from farm animals in Northeast Brazil. Res Vet Sci. 2013;94(3):587-9.
6. Mendes NHD, Oliveira CBS, Garcia CA, Holanda CMXC, Andrade-Neto VF. Epidemiological and serological profiles of ocular toxoplasmosis in the municipality of natal, northeastern Brazil. Trans R Soc Trop Med Hyg. 2014;108(10):656-61.

7. Oliveira CBS, Meurer YSR, Andrade JMA, Costa MESM, Andrade MCM, Silva LA, et al. Pathogenicity and phenotypic sulfadiazineresistance of isolates of Toxoplasma gondii obtained from livestock at northeastern in Brazil. Mem Inst Oswaldo Cruz. 2016;111(6):391-8. 